\title{
Analysis of Young Driver Behaviour related to Road Safety Issues in Pakistan and Hungary
}

\author{
Danish Farooq, Janos Juhasz \\ Budapest University of Technology and Economics \\ Department of Transport Technology and Economics, 1111, Budapest, Hungary \\ Farooq.danish@mail.bme.hu; janos.juhasz@mail.bme.hu
}

\begin{abstract}
Young Driver behaviour plays a key role in road safety as it is important in traffic accident prevention. This study designed to develop an initial set of measures to observe young driver behaviour related to road traffic safety issues in different countries. Driver Behaviour Questionnaire (DBQ) was designed to elicit useful information related to road safety from university students having driving licence. The main consideration taken on drivers attitudes towards traffic safety issues were failing to comply with a traffic light signal, failing to wear the seat belt, disregard the speed limits, failing to use personal intelligent driver assistant, failing to yield pedestrian, driving too close, frequently changing lanes, risk due to encroachments, failing to apply brakes, problems of mixed traffic and sounds horn in annoyance. Several differences in driving attitudes between Pakistan and Hungary drivers were identified. The utilization of observed measures provided richer information about deviant young driver behaviour. The analysis of the young drivers' perception on traffic safety issues quantify significant factors associated with them. From comparative studies of questionnaire data, it was noticed that Budapest drivers appear more disciplined than Islamabad drivers. But still there are some important young driver attitudes in both countries which need improvements for safe movements on the road.
\end{abstract}

Keywords: Young Driver Behaviour, Road Safety Issues, Driver Behaviour Questionnaire (DBQ), Comparative Study, Statistical Analysis.

\section{Introduction}

Many research studies focused solely on identifying the fundamental factors that cause road crashes. From these studies, it was noticed that human factors have the most significant impact on accident risk. The basic factors influence on road safety directly related to the driver are i.e., driver's perception of traffic risks, driving experience, and driving behaviour [1]. Drivers involve frequently in behaviours that cause safety issues to both themselves and to other road users also. Many of these attitudes are dynamic, conscious rule violations, while others are the result of errors due to less driving experience, momentary mistakes, inattention or failure to perform function, the latter often related to age. These behaviours often contribute to traffic collisions [2] [3]. Besides of risky driver behaviour the bad driving practices and poor knowledge along with disrespect for road and safety regulations are the obvious problems [4].

The study estimated that novice and younger drivers use the road-ways in large numbers as compared to older drivers. The young drivers driving difficulties are distinct and can be evaluated [5]. The novice young drivers suffer more risk due to over-representation in road injuries. To deal this problem effectively, a better understanding of the driving behaviour of novice young drivers and of its factors is needed [6]. The traffic safety related factors of young drivers causing accidents were noticed such as inattention, distraction and aggressive behaviour [7] [8]. The consistency and conversely, the differences in young driver behaviour, and the factors causing crash risk, may differ due to situation based specific factors [9].

The study determined that driver behaviour and the rate of traffic accidents vary in different countries. The differences in driver behaviour with respect to countrywide reveal variations in traffic risk perception [10]. It is well known that there are significant differences between countries in driving practice [11]. The cultural differences were studied in risk perception and approaches towards traffic safety and risk taking behaviour in Ghana and Norway. It was found that adolescent drivers were intense to take risks in traffic compared to older adults in both countries [12]. The study was carried to find the differences in perceived risks of traffic accidents in different countries where perceived risk of traffic 
accidents was compared in Japanese and a North American sample. The results indicated that respondents in the Japanese sample projected higher risk of traffic accidents than participants in the North American sample [13].

To assess deviant driving behaviour, the Driver Behaviour Questionnaire (DBQ) was first developed as a tool in the related studies 1990s [14] [15]. Among the many tools developed to identify problematic driver behaviours, the Driver Behaviour Questionnaire (DBQ) stands out for its longevity and dominant use. There has been substantial effort made to detect and remediate behaviours that decrease driving safety [16] [17].

The analysis of variance (ANOVA) was applied in study on DBQ item and scale scores to study whether there were significant differences between countries after controlling the effect of sex, age, and annual miles traveled within the sample. In order to examine the relationship between driving behaviour and the number of traffic accidents in each country, regression analyses was performed by using forward stepwise procedure. The level of $p<0.05$ was set as the cutoff value for significance [18]. Another study the one-way ANOVA analysis was also used to measure significance level of drivers on risk-taking behaviour of each of the nine questions related to their psychosocial function. Results showed that the level of risk-taking behaviour was significantly related to psychosocial function of driving, leisure time activities including driving related interaction with friends and educational attainment [19].

In this paper, driver behaviour questionnaire (DBQ) study was made on young driver behaviour related to traffic safety issues while driving. A survey was designed and conducted in two different contexts: the city of Budapest, which is located in center of Hungary, and the city of Islamabad, which is located in the northeast of Pakistan. The questionnaire consists of 11 items to investigate the young driver responses towards driving safety subjects. The students of universities who drive cars were communicated for their opinions on certain characteristics of driving attitudes related to traffic safety while driving. The results showed significant differences in driver attitudes towards traffic safety issues along with some similarities in the regions. The statistical analysis was applied on the data collected from the surveys to characterize the road users' driving behaviour, to evaluate significance level of items and factors that most affect the young driver's perception of traffic safety issues. The results in the study could be useful in terms of consideration that which driver attitudes are the most important one's which need improvements for safe movements on the road.

\section{Methodology}

\subsection{Sample}

Driver Behaviour Questionnaire (DBQ) was designed to measure young driver behaviour towards road traffic safety issues. The DBQ questionnaire included 11 items of such driving attitudes consists of closed questions, that is, multiple choices on three point scale ( $1=$ often, $2=$ sometimes, $3=$ never) for the convenience of statistical analysis. The research assistants asked the participants to indicate how often they have involved asked questionnaire behaviour while driving in recent one year.

The questionnaire was designed in English originally, and this version was used in Islamabad. And it was translated into a Hungarian language and this version was used in Budapest. A total of $(\mathrm{N}=70)$ students of universities who have at least one year driving experience were sampled from each region for this study. DBQ questionnaire data was collected by mail survey from university students of Islamabad with the help of research assistant. The response rate was $75 \%$. A Hungarian language version of the same questionnaire was distributed among university students in Budapest. For this purpose, individuals were approached and interviewed using the questionnaire. The demographic characteristics of respondents related to age, gender and driving experience were mentioned below in table 1 .

Table 1: Sample characteristics.

\begin{tabular}{|l|l|l|}
\hline Variables & Budapest & Islamabad \\
\hline $\mathrm{N}$ & 70 & 70 \\
\hline Age & & \\
Mean & 22.52857 & 20.98571 \\
SD & 2.25042 & 2.545202 \\
\hline Gender $(1=$ male, $0=$ female $)$ & & \\
Mean & 0.760563 & 0.84507 \\
SD & 0.42977 & 0.364413 \\
\hline Driving Experience & & \\
Mean & 2.357143 & 1.67429 \\
SD & 1.03698 & 0.928165 \\
\hline
\end{tabular}




\section{Data Analysis and Results}

The results of the study revealed the reported attitudes of young drivers towards traffic risks related to road safety. Table 2 provides information of driver behaviour questionnaire items with responses and the frequency levels related to road safety subjects and with distraction or psychophysical alteration while driving. Mostly young drivers in Budapest stated that they respect the driving safety values with a high frequency but for some items in driver behaviour questionnaire (DBQ), the drivers selected only 'sometimes' with high percentage such as disregard speed limits (62.9\%), driving too closely $(57.2 \%)$, frequently changing lines $(62.9 \%)$ and failing to use of personal intelligent system (54.3\%). While, comparatively lower percentage of Islamabad young drivers stated that they respect the driving safety values with a high frequency. The highest percentage of young driver's perception on traffic safety issues in Islamabad was estimated for failing to use of personal intelligent system (68.6\%). In other items of driver behaviour questionnaire (DBQ) they also selected only 'sometimes' with high percentage such as failing to wear seat belt (50\%), disregard speed limit (45.7\%) and problems of mixed traffic (48.6\%). Some road safety subjects were respected in both sample of respondents such as failing to yield pedestrian rules was responded 'never' in both groups (approximately $72.9 \%$ of Budapest drivers and $64.3 \%$ of Islamabad drivers) and failing to apply brakes rules was responded 'never' in both groups (approximately 64.3\% of Budapest drivers and $54.3 \%$ of Islamabad drivers).

Descriptive statistics was also applied to investigate the means and standard deviations of 11 items on the DBQ questionnaire in the samples as shown in table 2. The most frequently reported traffic issues reported by Budapest respondents were the failing to use personal intelligent assistant and frequently changing lanes which had the lowest mean of 1.94 whilst risk due to encroachments was the least reported issue by respondents which had mean of 2.78. While, the most frequently reported traffic issue reported by Islamabad respondents was the failing to use personal intelligent system which had the mean of 1.47 whereas failing to yield pedestrian was the least reported issue by respondents which had mean of 2.47 .

Table 2: Driver behaviour questionnaire (DBQ) results.

\begin{tabular}{|c|c|c|c|c|c|c|c|c|c|}
\hline \multicolumn{2}{|l|}{ Questionnaire } & \multicolumn{4}{|l|}{ Budapest } & \multicolumn{4}{|l|}{ Islamabad } \\
\hline How likely Did You? & Options & Frequency & $\%$ & $\mathrm{M}$ & SD & Frequency & $\%$ & $\mathrm{M}$ & SD \\
\hline $\begin{array}{l}\text { Failing to comply } \\
\text { with traffic light } \\
\text { signal }\end{array}$ & $\begin{array}{l}\text { 1)Often } \\
\text { 2)Sometimes } \\
\text { 3)Never }\end{array}$ & $\begin{array}{l}03 \\
12 \\
55\end{array}$ & $\begin{array}{l}4.3 \\
17.1 \\
78.6\end{array}$ & 2.74 & 0.52 & $\begin{array}{l}23 \\
26 \\
21\end{array}$ & $\begin{array}{l}32.9 \\
37.1 \\
30\end{array}$ & 1.97 & 0.79 \\
\hline $\begin{array}{l}\text { Failing to wear seat } \\
\text { belt }\end{array}$ & $\begin{array}{l}\text { 1)Often } \\
\text { 2)Sometimes } \\
\text { 3)Never }\end{array}$ & $\begin{array}{l}04 \\
14 \\
52\end{array}$ & $\begin{array}{l}5.7 \\
20 \\
74.3\end{array}$ & 2.68 & 0.57 & $\begin{array}{l}23 \\
35 \\
12\end{array}$ & $\begin{array}{l}32.9 \\
50 \\
17.1\end{array}$ & 1.84 & 0.69 \\
\hline Disregard speed limit & $\begin{array}{l}\text { 1)Often } \\
\text { 2)Sometimes } \\
\text { 3)Never }\end{array}$ & $\begin{array}{l}14 \\
44 \\
12\end{array}$ & $\begin{array}{l}20 \\
62.9 \\
17.1\end{array}$ & 1.97 & 0.60 & $\begin{array}{l}25 \\
32 \\
13\end{array}$ & $\begin{array}{l}35.7 \\
45.7 \\
18.6\end{array}$ & 1.83 & 0.72 \\
\hline $\begin{array}{l}\text { Failing to use } \\
\text { personal intelligent } \\
\text { assistant }\end{array}$ & $\begin{array}{l}\text { 1)Often } \\
\text { 2)Sometimes } \\
\text { 3)Never }\end{array}$ & $\begin{array}{l}18 \\
38 \\
14 \\
\end{array}$ & $\begin{array}{l}25.7 \\
54.3 \\
20 \\
\end{array}$ & 1.94 & 0.67 & $\begin{array}{l}48 \\
11 \\
11 \\
\end{array}$ & $\begin{array}{l}68.6 \\
15.7 \\
15.7\end{array}$ & 1.47 & 0.75 \\
\hline $\begin{array}{l}\text { Failing to yield } \\
\text { pedestrian }\end{array}$ & $\begin{array}{l}\text { 1)Often } \\
\text { 2)Sometimes } \\
\text { 3)Never }\end{array}$ & $\begin{array}{l}05 \\
14 \\
51\end{array}$ & $\begin{array}{l}7.1 \\
20 \\
72.9\end{array}$ & 2.66 & 0.61 & $\begin{array}{l}12 \\
13 \\
45\end{array}$ & $\begin{array}{l}17.1 \\
18.6 \\
64.3\end{array}$ & 2.47 & 0.77 \\
\hline Driving too closely & $\begin{array}{l}\text { 1)Often } \\
\text { 2)Sometimes } \\
\text { 3)Never }\end{array}$ & $\begin{array}{l}05 \\
40 \\
25\end{array}$ & $\begin{array}{l}7.1 \\
57.2 \\
35.7\end{array}$ & 2.28 & 0.58 & $\begin{array}{l}19 \\
29 \\
22\end{array}$ & $\begin{array}{l}27.1 \\
41.5 \\
31.4\end{array}$ & 2.04 & 0.76 \\
\hline $\begin{array}{l}\text { Frequently changing } \\
\text { lanes }\end{array}$ & $\begin{array}{l}\text { 1)Often } \\
\text { 2)Sometimes } \\
\text { 3)Never }\end{array}$ & $\begin{array}{l}15 \\
44 \\
11 \\
\end{array}$ & $\begin{array}{l}21.4 \\
62.9 \\
15.7 \\
\end{array}$ & 1.94 & 0.60 & $\begin{array}{l}32 \\
24 \\
14 \\
\end{array}$ & $\begin{array}{l}45.7 \\
34.3 \\
20\end{array}$ & 1.74 & 0.77 \\
\hline $\begin{array}{l}\text { Risk due to } \\
\text { encroachments }\end{array}$ & $\begin{array}{l}\text { 1)Often } \\
\text { 2)Sometimes } \\
\text { 3)Never }\end{array}$ & $\begin{array}{l}0 \\
15 \\
55\end{array}$ & $\begin{array}{l}0 \\
21.4 \\
78.6\end{array}$ & 2.78 & 0.41 & $\begin{array}{l}05 \\
31 \\
34\end{array}$ & $\begin{array}{l}7.1 \\
44.3 \\
48.6\end{array}$ & 2.41 & 0.62 \\
\hline
\end{tabular}




\begin{tabular}{|l|l|l|l|l|l|l|l|l|l|}
\hline Failing to apply & 1)Often & 0 & 0 & 2.64 & 0.48 & 08 & 11.4 & 2.43 & 0.69 \\
brakes & 2)Sometimes & 25 & 35.7 & & & 24 & 34.3 & & \\
& 3)Never & 45 & 64.3 & & & 38 & 54.3 & & \\
\hline Problems of mixed & 1)Often & 07 & 10 & 2.38 & 0.66 & 20 & 28.6 & 1.94 & 0.71 \\
traffic & 2)Sometimes & 29 & 41.4 & & & 34 & 48.6 & & \\
& 3)Never & 34 & 48.6 & & & 16 & 22.8 & & \\
\hline Sounds horn in & 1)Often & 07 & 10 & 2.47 & 0.67 & 33 & 47.1 & 1.73 & 0.77 \\
annoyance & 2)Sometimes & 23 & 32.9 & & & 23 & 32.9 & & \\
& 3)Never & 40 & 57.1 & & & 14 & 20 & & \\
\hline
\end{tabular}

In the ANOVA analysis table, the total degrees of freedom (DF) show how much information that data uses. DF is calculated by total number of values in an independent variable source minus one, e.g. in this study, there are total two groups of drivers in sample, so its degrees of freedom (DF) is calculated by two minus one, i.e. one as shown in second column of table 3. Mean squares describes that how much a term or model displays variation, assuming that all other terms are in the model, irrespective of the order they were entered. Mean square is calculated by dividing the sum of square values by degree of freedom. In this case values of sum of square and mean square are same because value of degree of freedom was measured one for all items in sample. The values of mean squares are shown in column 3 of table 3. F-value is the statistical test used to determine whether the term is related with the response variable or not. F-value is used to calculate the significance value on risk taking behaviour in the sample. F-values have been computed for all the questionnaire items in sample as shown in column 4 of table 3 . The p-value is a probability that measures the evidence against the null hypothesis. There are two parameters to check the significance of items in sample which are; the F-values should be greater than F-critical and p-value $<\alpha$-value. So, if F-value is greater from F-critical and p-value is lower from 0.05 then the effect for that term is statistically significant. If the Pvalue is larger than the selected significance level $(\alpha)$, the effect is not statistically significant. The results showed that mostly terms in sample are statistically significant because their F-values are greater than F-critical and p-value less than 0.05 . Only three terms are not statistically significant such as disregard speed limit, failing to yield pedestrian and frequently changing lanes which have $\mathrm{F}$ value less then $\mathrm{F}$ critical and $\mathrm{p}$-value greater than 0.05 . The statistical analysis results have been shown in table 3 .

Table 3: ANOVA analysis results after controlling the effect of gender, age and driving experience.

\begin{tabular}{|l|l|l|l|l|l|}
\hline Questionnaire Items & df & MS & F & P-value & F-critical \\
\hline $\begin{array}{l}\text { Failing to comply with traffic light } \\
\text { signal }\end{array}$ & 1 & 20.82857 & 45.39801 & 0.000 & 3.909729 \\
\hline Failing to wear seat belt & 1 & 24.86429 & 60.88441 & 0.000 & 3.909729 \\
\hline Disregard speed limit & 1 & 0.714286 & 1.592798 & 0.209056 & 3.909729 \\
\hline $\begin{array}{l}\text { Failing to use personal intelligent } \\
\text { assistant }\end{array}$ & 1 & 7.778571 & 15.07342 & 0.000 & 3.909729 \\
\hline Failing to yield pedestrian & 1 & 1.207143 & 2.478427 & 0.117707 & 3.909729 \\
\hline Driving too closely & 1 & 2.064286 & 4.372068 & 0.038366 & 3.909729 \\
\hline Frequently changing lanes & 1 & 1.4 & 2.877447 & 0.092083 & 3.909729 \\
\hline Risk due to encroachments & 1 & 4.828571 & 17.18644 & 0.000 & 3.909729 \\
\hline Failing to apply brakes & 1 & 1.607143 & 4.506531 & 0.035551 & 3.909729 \\
\hline Problems of mixed traffic & 1 & 6.864286 & 14.27535 & 0.000 & 3.909729 \\
\hline Sounds horn in annoyance & 1 & 19.31429 & 36.36959 & 0.000 & 3.909729 \\
\hline
\end{tabular}

\subsection{Comparison Plots}

Fig. 1 showed comparison column charts between two groups (Budapest and Islamabad) for percentage of drivers who responded the option 'often' from 11 items of questionnaire. The percentage of difference between two groups was observed higher (>25\%) in some items such as Q1 (28.6\%), Q2 (27.2\%), Q4 (42.9\%) and Q11 (37.1\%). While, other cases the percentage of difference was observed lower $(<25 \%)$ between items of two groups. 


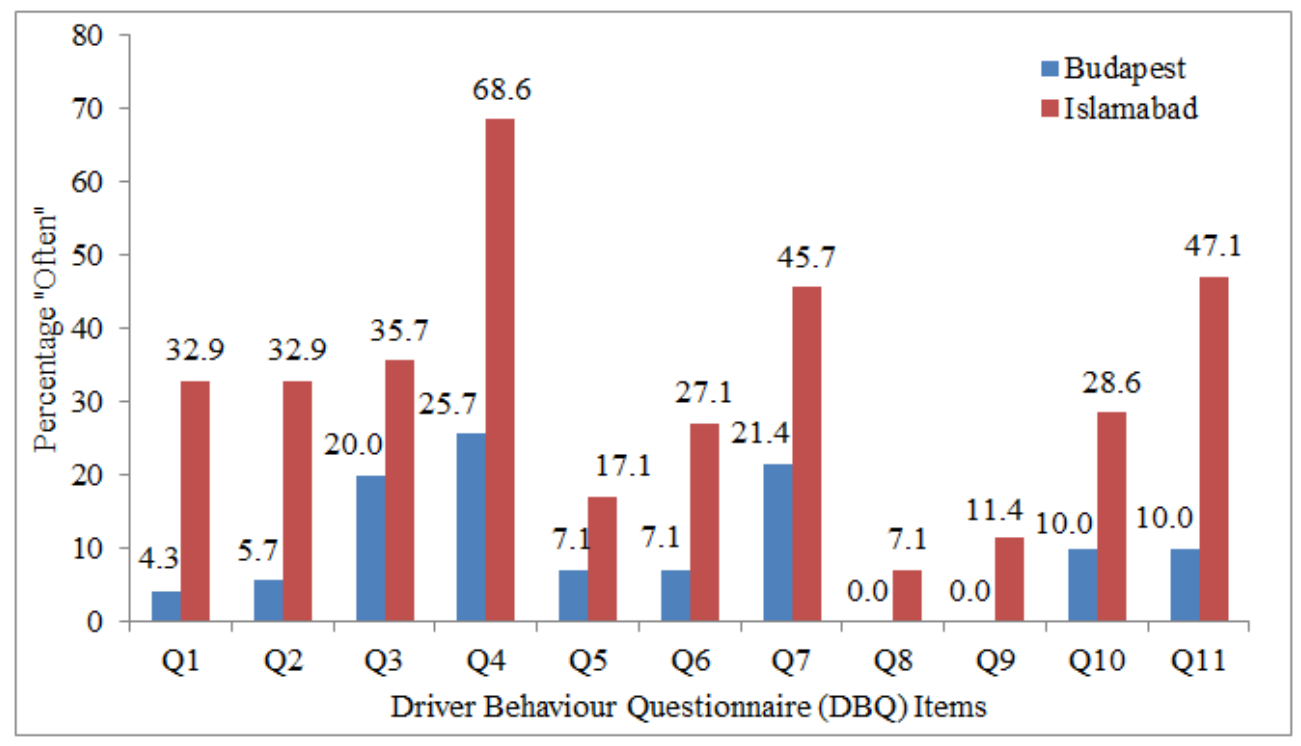

Fig. 1: Comparison charts for driver's response "Often".

Fig. 2 showed comparison column charts between two groups (Budapest and Islamabad) for percentage of drivers who responded the option 'never' from 11 items of questionnaire. The percentage of difference was observed higher $(>25 \%)$ between two groups in some items such as Q1 (48.57\%), Q2 (57.14), Q8 (30\%), Q10 (25.72) and Q11 (37.14). While, other cases the percentage of difference was observed lower $(<25 \%)$ between items of two groups.

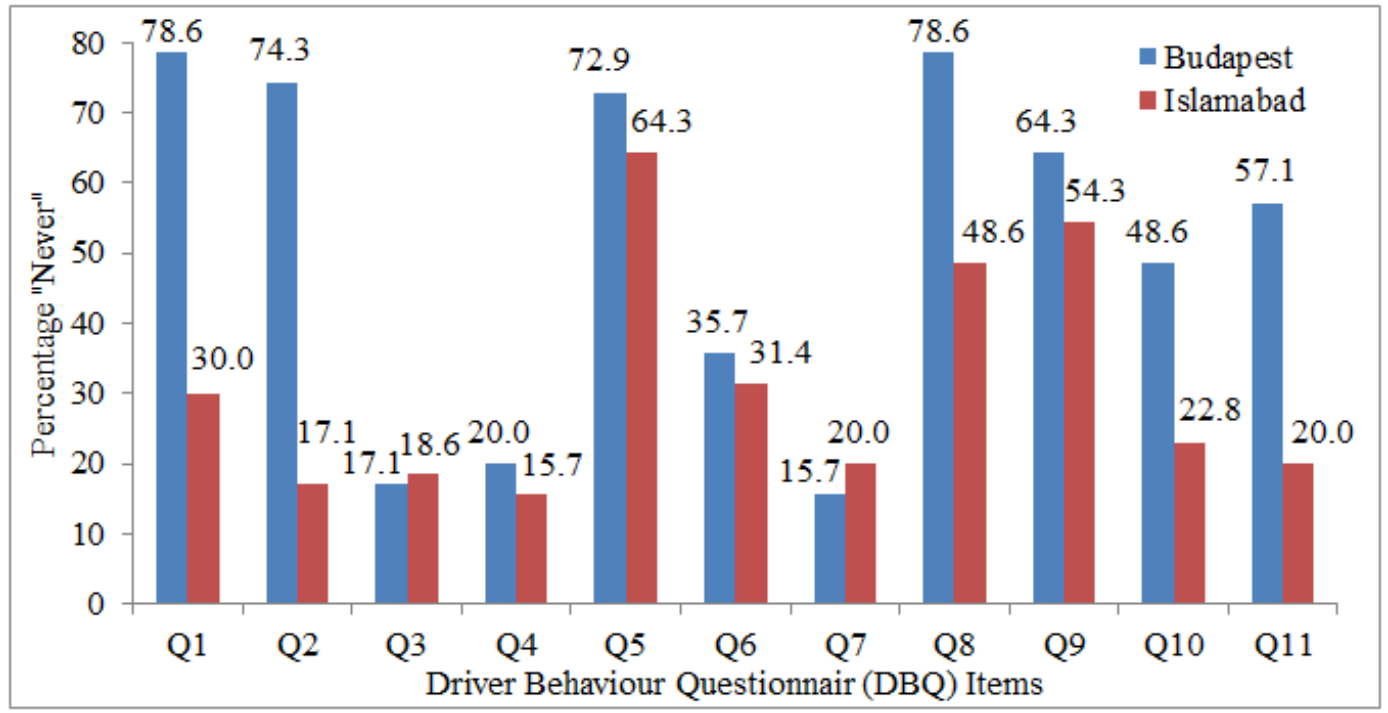

Fig. 2: Comparison charts for driver's response "Never".

\section{Conclusions}

This paper investigated young driver behaviour and attitudes with the help of self-assessment driver behaviour questionnaire (DBQ) to identify the factors that most affect driver perception towards road traffic safety issues. For this purpose, the individuals $(\mathrm{N}=70)$ of university students having driving license were approached and interviewed in Budapest on Hungarian language version of questionnaire. The Islamabad university students having driving license responded through email on English language version of questionnaire. From the results of the respondents, many significant differences were measured in many young driver attitudes such as failing to wear seat belt, sounds horn in annoyance, failing to comply traffic light signal, failing to use personal intelligent system and problems of mixed traffic between two regions. However, the results obtained from the samples also showed some similarities in some young driver 
attitudes such as failing to yield pedestrian and failing to apply brakes in both regions. The factor analysis indicated that some important young driver behaviours such as disregarding the speed limits, driving too closely and frequently changing lanes need improvements in both countries. The statistical analysis results suggested the significance of items in sample. In general, the comparisons suggested that the driving behaviour of the young drivers in Budapest is more compliant with the driving safety approaches than that of drivers in Islamabad. The traffic regulation authorities in Pakistan should take solid steps to mitigate pointed traffic safety issues of young drivers. These results can play an important role in planning road safety campaigns in universities on pointed issues of young drivers in both regions. The limitation of this study is that participants might not clearly explain their behaviour on self-reported questionnaire study. Concerning future research needs, it is recommended to examine young drivers' behaviour using driving simulators or other advance naturalistic tools to compare the actual behaviour with the self-reported behaviour presented in the current study.

\section{References}

[1] J.de Oña, R. de Oña, L. Eboli, C. Forciniti, G. Mazzulla, "How to identify the key factors that affect driver perception of accident risk, A comparison between Italian and Spanish driver behaviour," Accident Analysis and Prevention, vol. 73, pp. 225-235, 2014.

[2] N. A. Stanton and P. M. Salmon, "Human error taxonomies applied to driving: generic driver error taxonomy and its implications for intelligent transport systems," Safety Science, vol. 47, pp. 227-237, 2009.

[3] W. W. Wierwille, R. J. Hanowski, J. M. Hankey, C. A. Kieliszewski, S. E. Lee, A. Medina, A. S. Keisler, T. A. Dingus, "Identification and evaluation of driver errors: overview and recommendations," U.S Department of Transportation, Federal Highway Administration, Report No. FHWA-RD-02-003, 2002.

[4] A. Lindgren, F. Chen, P. W. Jordan, H. Zhang, "Requirements for the design of advanced driver assistance systems - the differences between Swedish and Chinese drivers," International Journal of Design, vol. 2, no. 2, pp. 41-54, 2008 .

[5] W. Boot, C. Scialfa, "The aging road user and technology to promote safe mobility for life," In: Kwon, S. (Ed.), Gerontechnology, Springer, New York (inpress), 2016.

[6] C. G. Prato, T. Toledo, T. Lotan, O. Taubman-Ben-Ari, "Modeling the behaviour of novice young drivers during the first year after licensure," Accident Analysis \& Prevention, vol. 42, no. 2, pp. 480-486, 2010.

[7] M. A. Regan and J. D. Lee, T. W. Victor, "Driver Distraction and Inattention," Advances in Research and Countermeasures, vol. 1, Ashgate, Farnham, UK, 2013.

[8] H. Stanislaw, "Personality and demographic predictors of aggressive and distracted driving," In: Sullman, M., Dorn, L. (Eds.), Advances in Traffic Psychology, Surrey, UK, pp. 63-75, 2012.

[9] B. Scott-Parker and C. Proffitt, "Validation of the behaviour of young novice drivers scale (BYNDS) in a New Zealand young driver population," Accid. Anal.Prev., vol. 77, 62-71, 2015.

[10] T. Lajunen, A. Corry, H. Summala, L. Hartley, "Cross-cultural differences in drivers' self-assessments of their perceptual-motor and safety skills: Australians and Finns," Personality and Individual Differences, vol. 24, 539-550, 1998.

[11] T. Ozkan, T. Lajunen, H. Summala, "Driver Behaviour Questionnaire: a follow-up study," Accident Analysis and Prevention, vol. 38, no. 2, pp. 386-95, 2006.

[12] I. O. Lund and T. Rundmo, "Cross-cultural comparisons of traffic safety, risk perception, attitudes and behaviour," Safety Science, vol. 47, no. 4, pp. 547-553, 2009.

[13] H. Hayakawa, P. S. Fischbeck and B. Fischhoff, "Automobile risk perceptions and insurance-purchasing Decisions in Japan and the United States," Journal of Risk Research, vol. 3, pp. 51-67, 2000.

[14] D. Parker, J. T. Reason, A. S. R. Manstead, S. G. Stradling, "Driving errors, driving violations and accident involvement," Ergonomics, vol. 38, pp. 1036-1048, 1995.

[15] J. T. Reason, A. S. R. Manstead, S. Stradling, J. Baxter, K. Campbell, "Errors and violations on the roads," Ergonomics, vol. 33, pp. 1315-1332, 1990.

[16] A. af, Wåhlberg, L. Dorn, T. Kline, "The Manchester driver behaviour questionnaire as a predictor of road traffic accidents," Theory, Issues Ergonomics, Sci., vol. 12, pp. 66-86, 2011.

[17] J. C. F. de Winter, D. Dodou, "The Driver Behaviour Questionnaire as a predictor of accidents: A meta-analysis," Journal of Safety Research, vol. 41, no. 6, pp. 463-470, 2010. 
[18] D. Lord, S. P. Washington, J. N. Ivan, Poisson, "Poisson-gamma and zero-inflated regression models of motor vehicle crashes: balancing statistical fit and theory," Accident Analysis and Prevention, vol. 37, 35-46, 2005.

[19] M. Møller and N. P. Gregersen, "Psychosocial function of driving as predictor of risk-taking behaviour," Accident Analysis and Prevention, vol. 40, pp. 209-215, 2008. 